\title{
O jogo com regras pode ser instrumento para modificar o fracasso escolar?
}

\author{
Silva Nara Siqueira Pinheiro* \\ Maria Laura Oliveira Couto**
}

\section{Resumo}

Este trabalho apresenta uma das três intervenções efetivadas na pesquisa de doutorado que teve como objetivo investigar se o jogo com regras explícitas influencia o desenvolvimento das funções psicológicas superiores (FPS) de alunos com história de fracasso escolar no ensino fundamental. Ancora-se na psicologia histórico-cultural. A pesquisa adota o método genético-experimental e consiste em uma intervenção, por meio dos jogos de memória, cara a cara e damas, realizada com um aluno de 11 anos que estava repetindo o $3^{\mathbf{o}}$ ano do ensino fundamental. Os instrumentos utilizados foram entrevistas semiestruturadas com a família, professores e alunos; boletim escolar; observação e avaliação assistida dos testes WISC III e TDE junto ao aluno. As análises dos dados foram microgenética e temática. Os resultados indicam que a intervenção gerou desenvolvimento das FPS e mudanças no rendimento escolar. Conclui-se que o jogo foi um mediador eficiente entre a aprendizagem e o desenvolvimento do aluno.

Palavras-chave: Fracasso escolar. Jogo. Psicologia histórico-cultural.

*Doutora em Educação - Aprendizagem, pela Universidade Federal de Pelotas (UFPel). Professora do Curso de Psicologia da Universidade Federal de Pelotas (UFPel).

**Graduada em Psicologia pela Universidade Federal de Pelotas (UFPel).

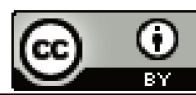




\section{Introdução}

Este trabalho apresenta uma das três intervenções efetivadas na pesquisa de doutorado queteve como objetivo investigar se o jogo com regras explícitas influencia o desenvolvimento das funções psicológicas superiores (FPS), o aprendizado e o comportamento de alunos com história de fracasso escolar no ensino fundamental. Ancora-se na psicologia histórico-cultural, principalmente nas ideias de Vygotsky e Elkonin.

Iniciando a análise do tema, a intervenção por meio de jogos nas FPS, na perspectiva históricocultural, parte da premissa que o indivíduo está inserido e é produto de um contexto histórico, social e econômico; que seu desenvolvimento psicológico está em constante movimento e mudança,em meio aos quais ele modifica a natureza e é modificado por ela. Um ser humano que vai se humanizando por meio das relações sociais que estabelece, mediadas por instrumentos psicológicos (signos) (VYGOTSKY, 2009); um ser humano que não nasce com suas FPS prontas e acabadas, mas que as desenvolve no decorrer de sua vida, principalmente pela aprendizagem; um ser humano em constante mudança e criativo.

Analisando o desenvolvimento das FPS, Vygotsky (1995) argumenta que a psicologia tradicional, ou não as investigava naquele momento histórico (1931), ou, quando o fazia, desenvolvia pesquisas equivocadas sobre elas. As funções não eram tomadas como processo, e sim como elementos isolados, perdendo seu caráter estrutural integral. A psicologia tradicional, para estudar as FPS, separava-as e as descrevia. Dessa maneira, não conseguia revelar os nexos causais e as relações que se fazem presentes entre elas. Para Vygotsky (1995), o importante é a análise do conjunto das FPS, que não pode ser considerado como uma simples soma dessas funções, pois inclui o processo de interrelação entre elas. Para estudá-las, não se pode simplesmente descrevê-las em seu aspecto exterior, mas se deve explicá-las em sua gênese.

Vygotsky (1995) defendia a ideia de que elas aparecem duas vezes: durante atividades coletivas, como funções interpsíquicas, e no âmbito individual, como funções intrapsíquicas, assumindo assim uma direção que vai do social para o individual. As FPS desenvolvem-se por meio de dois processos que estão indissociavelmente unidos: o orgânico (elementar) e o cultural (superior). As FPS são produtos do desenvolvimento social da conduta, das interações entre os homens. Para que se desenvolvam socialmente, faz-se necessário certo grau de maturidade biológica, ou seja, certa estrutura (VYGOTSKY, 1995). 
Vygotsky (1995) e colaboradores, objetivando estudar o desenvolvimento da atenção mediada, procurando identificar como ela, de um processo natural, transforma-se em cultural, realizaram vários experimentos, utilizando o método de dupla estimulação. Este método consistia em solicitar a tarefa de memorizar várias palavras (estímulo inicial) relacionadas a nomes de objetos. Em seguida, os sujeitos deveriam reproduzi-las. Posteriormente era oferecida uma série de cartões (estímulos auxiliares) contendo desenhos dos objetos representando as palavras, sem explicar como estes poderiam auxiliá-la na tarefa de memorização. Em outro momento era fornecida uma explicação (mediação) para que os sujeitos relacionassem palavras com os cartões correspondentes.

A partir dos resultados obtidos, os pesquisadores concluíram que existem diferenças no benefício da mediação em função da faixa etária. As crianças pré-escolares, com ou sem a mediação de estímulos externos, continuavam agindo com base no ensaio/erro. Elas não foram capazes de se beneficiar com a mediação de meios externos auxiliares (cometendo o mesmo número de erros nas duas situações), pois isso exige atenção concentrada, por longo período de tempo, para cumprir a tarefa exigida. E isso não foi possível porque suas FPS ainda não estavam bem desenvolvidas.

Nas crianças em idade escolar, constatou-se menor número de erros, quando o processo era mediado pelo adulto, utilizando estímulos auxiliares externos. Segundo Vygotsky (1995), em crianças dessa idade, ocorre uma reestruturação dos processos internos: as operações externas se convertem em internas. A mediação aumenta a capacidade de atenção e memória, permitindo o controle voluntário sobre seu comportamento.

Para unir desenvolvimento das FPS e aprendizagem, Vygotsky (2009) criou o conceito de zona de desenvolvimento iminente (ZDI) (PRESTES, 2010). Na ZDI estão os processos em desenvolvimento. Eles são como "brotos", não estão totalmente desenvolvidos e, portanto, necessitam da ajuda de outra pessoa para atingir um nível de desenvolvimento pleno, no qual as funções mentais atingem maior maturidade, assim a criança consegue resolver problemas com autonomia. $\mathrm{O}$ que, em um determinado momento, está na ZDI, em outro momento estará no nível de desenvolvimento atual, ou seja, o que a criança faz em colaboração hoje (nível de desenvolvimento potencial - NDP), amanhã poderá fazer sozinha. A ZDI permite vislumbrar os futuros passos da criança, a dinâmica do seu desenvolvimento, e não só examinar o que já está pronto. A ajuda do adulto ou de alguém mais adiantado pode ser efetivada por meio de perguntas, exemplos, demonstrações. A aprendizagem mediante demonstrações pressupõe imitação (VYGOTSKY, 1995, 2009).

Segundo Vygotsky (2009), a aprendizagem efetiva é aquela que se adianta e norteia o desenvolvimento, iniciando pelo que não está maduro e desencadeando o amadurecimento das funções 
psicológicas que estão na ZDI. A aprendizagem só é fecunda entre o limiar inferior, ou seja, o nível de desenvolvimento atual e o limiar superior, definido como potencial. Por isso, torna-se extremamente importante definir os dois limiares, pois é nesta zona que o professor deverá realizar sua intervenção. As interações que se transformam em desenvolvimento são aquelas que são dirigidas à zona de desenvolvimento iminente da criança (VYGOTSKY, 1995, 2009).

O desenvolvimento é uma construção que vai do social para o individual, do interpessoal para o intrapessoal, mas nem todo o ensino, nem toda a interação social, nem todo o jogo gera uma evolução; isso ocorre somente com aqueles que, partindo do ponto em que a criança se encontra, são capazes de levá-la mais além (VYGOTSKY, 1995, 2009).

Vygotsky (2002, 2008) e Elkonin (2009), ao estudar o jogo infantil, afirmam que a relação do jogo com o desenvolvimento é semelhante àquela entre a aprendizagem e o desenvolvimento, ou seja, a brincadeira é fonte do desenvolvimento cognitivo e emocional e cria zonas de desenvolvimento iminente. O tema jogo foi abordado pela primeira vez por Vygotsky em 1933, em uma conferência realizada no Instituto Gertsen de Pedagogia, em Leningrado, intitulada A brincadeira e o seu papel no desenvolvimento psíquico da criança, publicada em 1966. Seu interesse por este assunto surgiu dos estudos realizados na área de psicologia do desenvolvimento infantil, no que tange às funções psíquicas superiores e à psicologia da arte.

Vygotsky (2002, 2008), em seus estudos, não realizou distinção entre jogo e brincadeira, utilizando-os como sinônimos, no sentido de brincadeira ou jogo-de-faz-de-conta e de regras. A palavra igra, em russo, quer dizer tanto jogo como brincadeira. Elkonin (2009, p. 19) define que o jogo "é uma atividade em que se reconstroem, sem fins utilitários diretos, as relações sociais”. No presente trabalho, utilizar-se-á a palavras jogo em menção a uma atividade composta de diferentes ações,cujo objetivo está, na idade pré-escolar, no próprio processo de sua realização e, na idade escolar, no seu produto (VYGOTSKY, 2002, 2008; LEONTIEV, 1988).

$\mathrm{Na}$ revisão de pesquisas sobre o jogo, verificou-se que ele é enfocado por diferentes áreas e, nelas, por diferentes teóricos. Grande parte das pesquisas desenvolvidas na perspectiva históricocultural focam o jogo na educação infantil (BALDAN; ARCE, 2007; ROLIM; GUERRA; TASSIGNY, 2008; NASCIMENTO; MIGUÉIS; ARAÚJO, 2009; NASCIMENTO; ARAÚJO, 2010; SOUZA, 2010; BALDAN; HAI, 2011). Apresentam análises teóricas sobre o jogo, enfatizam a relação do lúdico com o desenvolvimento e a aprendizagem, argumentando que o jogo desenvolve as FPS, cria a zona de desenvolvimento proximal e, por fim, possibilita à criança apropriar-se da cultura. Segundo os autores, 
para que se efetive essa relação, faz-se necessária a intencionalidade na educação e na ação do educador, que deve guiar/dirigir o processo de ensino e aprendizagem.

No ensino fundamental, estendendo-se o foco de pesquisa aos professores, foi encontrada a pesquisa de Pimentel (2008), cuja conclusão afirma que o jogo é importante para o aprendizado, mas que os professores não estão preparados para sua adequada utilização.

$\mathrm{Na}$ busca por pesquisas sobre o jogo de regras explícitas, nessa abordagem e no ensino fundamental, tendo como amostra alunos com e sem fracasso escolar, foram encontrados os trabalhos de mestrado e doutorado de Fittipaldi (2007, 2009). Ambos adotaram o jogo das boas perguntas (JBP) e a mesma metodologia de estudo de casos, com pré-teste, intervenção e pós-teste.

O primeiro estudo (2009) objetivou verificar se crianças do ensino fundamental adquirem novos conhecimentos, desenvolvem novas habilidades e fazem uso de novas estratégias cognitivas. Teve como amostra 4 meninos, com 9 anos de idade que cursavam a $3^{\text {a }}$ série do Ensino Fundamental. No pré-teste, a autora escolheu um com resultados acima da média esperada para a idade e série; um na média e dois com resultados abaixo do esperado para a idade e série. As conclusões gerais obtidas pela pesquisadora são que o jogo de regras explícitas, com apoio da mediação, promove um desenvolvimento que expande as possibilidades de aprendizagem e melhora a autoestima.

O segundo trabalho de Fittipaldi (2007) objetivou constatar se o jogo pode ser um recurso pedagógico capaz de promover a construção de conceitos escolares e desenvolver habilidades cognitivas em interação com pares mais experientes. Sua amostra foi composta por 4 alunos do sexo masculino, com 10 anos de idade, que cursavam a $4^{\text {a }}$ série do Ensino Fundamental da Rede Pública. Os resultados indicaram que o jogo possibilita que se identifique a maneira como o aluno pensa; os motivos que o levaram a realizar a jogada; o que ele resolve sozinho, seu nível de desenvolvimento real. Identifica suas dificuldades e as ajudas que são necessárias para criar zonas de desenvolvimento proximal. A autora conclui que é um recurso importante no processo de aprendizagem e desenvolvimento das FPS. Impulsiona o desenvolvimento cognitivo e permite, também, a aquisição de novos conhecimentos.

Apartir do exposto, acredita-se que o jogo possa ser um caminho para o desenvolvimento das FPS (percepção, atenção, memória, tomada de consciência, raciocínio e outras), o que reverberará no desempenho escolar do estudante que apresenta dificuldades em termos de aprendizagem escolar. Pensa-se que o jogo de regras, utilizado no contexto de intervenções individualizadas, possa ser um instrumento para modificar o fracasso escolar, entendido, neste trabalho, como dificuldade na leitura, escrita, cálculo e repetência. A seguir serão demonstrados os achados desta pesquisa. 


\section{Método}

A pesquisa caracterizou-se como uma intervenção estruturada em três etapas: avaliação inicial, intervenção e avaliação após a intervenção (DAMIANI et al., 2013), bem como no método genético experimental (VYGOTSKY, 1995). Os jogos utilizados na intervenção foram o de "memória", "cara a cara" e "damas". Estes foram mediados pela linguagem da pesquisadora, constituíram-se no estímulo externo, usado para desenvolver as FPS que poderiam, em consequência, auxiliar na aprendizagem do sujeito, caracterizando o princípio da dupla estimulação (VYGOTSKY, 1995). A intervenção a ser apresentada foi realizada com um aluno de 11 anos que repetiu duas vezes o $2^{\circ}$ ano e uma vez o $3^{\circ}$ do ensino fundamental. O sujeito é proveniente de uma família de baixa renda, seus pais são separados e ele toma medicação para convulsões. Foi selecionado, em conjunto com a professora, por meio da análise do seu histórico escolar.

Os instrumentos utilizados para coleta dos dados na avaliação inicial e final do aluno foram o Teste de Desempenho Escolar (TDE) (STEIN,1994) e os subtestes de informação, compreensão, dígitos, semelhanças e o teste de completar figuras da Escala de Inteligência Wechsler para Crianças WISC - III (FIGUEIREDO, 2002). Cabe frisar que a aplicação dos instrumentos tentou identificar não só o que o sujeito sabia resolver sozinho, seu nível de desenvolvimento real (NDR), mas também o que estava em sua ZDI. Isso foi realizado a partir do apoio e da mediação da pesquisadora (LINHARES et al., 1998; VYGOTSKY, 2009). As avaliações do desempenho consistiram, assim, apenas em contagem de acertos e erros, com e sem auxílio. A utilização desses testes não contrariou os pressupostos da Teoria Histórico-cultural, pois, primeiro, não seguiu as instruções de aplicação e avaliação indicadas nos seus manuais, que visam avaliar o que o aluno já consegue fazer sozinho, comparando-o com uma norma. Essa aplicação reproduziu a conduta de Vygotsky (2009), quando realizou as investigações que levaram à construção do conceito de ZDI, nas quais utilizou testes. Portanto, a utilização dos instrumentos objetivou avaliar o desenvolvimento do sujeito antes e depois da intervenção.

Coma família e os professores, foram utilizadas entrevistas semiestruturadas. Os métodos de análise utilizados neste estudo tiveram caráter qualitativo, a saber: o microgenético (GÓES, 2000) e a análise de conteúdo do tipo temática (MINAYO, 1993). Todos os dados analisados sofreram processos de triangulação (DUARTE, 2009; YIN, 2010) entre si. Os encontros foram gravados, e as observações da pesquisadora foram anotadas em diário de campo (YIN, 2010). Nos relatos das falas da mãe, do aluno e do professor, bem como nos extratos da intervenção, não se realizará correções da língua portuguesa. Manter-se-á o mais fiel possível a fala dos sujeitos que fizeram parte deste estudo.A seguir, 
serão expostos os achados e discussão. Primeiro descrever-se-á a intervenção e posteriormente os seus efeitos no desenvolvimento das FPS, no desempenho acadêmico e no comportamento.

\section{Intervenção}

A intervenção ocorreu em 2012 e teve a duração de 14 encontros individuais. Ocorria semanalmente, na sala da orientadora educacional, durante o horário escolar, com tempo de duração ao redor de 40 minutos. Neles foram utilizados os jogos de "memória" (4 encontros), "cara a cara" (5 encontros) e "damas" (5 encontros). A sequência dos jogos foi estabelecida tomando-se como critério sua complexidade (começando do mais simples).

No primeiro encontro em que era proposto o uso de cada jogo, as regras desse jogo eram explicadas. Jogava-se a primeira partida sem possibilitar o apoio, para identificar o NDR do sujeito em relação a tal jogo, ou seja, o que ele sabia fazer de maneira autônoma. Nas partidas seguintes, conforme a necessidade, era fornecido apoio para que ele fosse aprendendo a jogar com mais adequação. Em todos os jogos as regras foram sempre retomadas quando se fazia necessário.

Constatou-se nos encontros que Vinícius, por vezes, no jogo de “memória”, desvirava uma peça e não permitia que a pesquisadora visse a figura que continha. Houve a necessidadede solicitar que o menino não agisse dessa forma e permitisse que a peça desvirada fosse olhada ("Vinícius, deixa eu olhar, tu tens que deixar eu olhar").

Não desenvolvia nenhuma estratégia de jogo, atuava por ensaio/erro, não pensava em suas jogadas, movia as peças no tabuleiro de qualquer maneira no jogo de "damas"; desvirava duas peças, no jogo de "memória" em uma jogada e, na seguinte, desvirava uma das abertas anteriormente, talvez porque já fosse conhecida, repetindo a jogada que não obteve êxito. Por exemplo: "Pesquisadora: Mas que confusão tu fizeste! Esse aqui é o homem de pedra não é? De novo, tu viraste a mesma peça."

Confundia-se em relação à carta que deveria descartar, não realizando o raciocínio de exclusão no jogo “cara a cara”. Por exemplo: “Tira os sem óculos agora ou com óculos?”. Descarte de figuras em demasia, ou não descarte, impossibilitando o término do jogo com sucesso. Repetia perguntas já realizadas, não percebia características comuns das figuras; em decorrência, não as agrupava para realizar uma boa pergunta, ou seja, que possibilitasse vários descartes. O menino justificava suas jogadas dizendo "Eu esqueço".

Nas partidas em que o jogo foi mediado pela pesquisadora e a intervenção direcionou-se à ZDI do aluno,chamava-se a atenção de Vinícius,no jogo de "memória", para a organização das peças, para as características e localização das figuras sobre a mesa- "Esse é o bombeiro, estava por aí! [apontava a 
localização]" -, para as jogadas repetitivas, trabalhando na ZDI a atenção, as estratégias de ação e a tomada de consciência de suas jogadas.

Uma das maneiras de mediação adotadas foi sentar ao lado do sujeito, no jogo "cara a cara", chamando a atenção para os detalhes das figuras que estavam no tabuleiro e formulando as perguntas em conjunto com ele. Auxiliá-lo nos descartes foi outro apoio possibilitado: por exemplo, em uma das partidas, a pesquisadora perguntou para Vinícius se havia no tabuleiro mais alguma figura com chapéu, ajudando-o a utilizar melhor sua percepção e atenção, melhorando suas jogadas. Outro exemplo foi pedir para ele olhar fila por fila para achar todas as figuras que deveriam ser descartadas. Ao retomar as regras do jogo "cara a cara", chamava a atenção de Vinícius para o limite de apenas três perguntas ao mesmo tempo, ressaltando que a primeira delas não poderia ser sobre o sexo da figura.

No jogo de “damas", a pesquisadora solicitava ao sujeito que analisasse o tabuleiro e percebesse as possibilidades de jogadas, analisava a sua jogada e a de Vinícius dizendo o que iria acontecer e sempre possibilitava que a modificasse, caso não estivesse adequada. Cabe a ressalva de que as FPS (atenção, memória, percepção, raciocínio, tomada de consciência e estratégias de ação) foram trabalhadas de maneira integrada em todos os encontros.

Por fim, a mediação consistiu: em repetir a fala da criança, traduzir e questionar suas jogadas, procurando fazer com que ela tomasse consciência sobre seu modo de jogar e, consequentemente, pudesse autorregular seu comportamento; fornecer modelos de raciocínio; incentivar o sujeito a imitar as jogadas da pesquisadora; ajudar, apoiar na realização de jogadas, dando dicas, analisando,corrigindo, solicitando explicações sobre elas, refletindo com a criança sobre suas estratégias, mostrando outras possibilidades de jogadas; e elogiar as boas jogadas realizadas - ações inspiradas nos procedimentos utilizados por Vygotsky (2009).

\section{Efeitos da intervenção por meio de jogos no desenvolvimento das FPS}

No decorrer dos encontros em que os jogos foram realizados com apoio, perceberam-se mudanças na maneira de jogar de Vinícius. Ele relatava as jogadas que iria realizar, demonstrando que estava pensando (tomada de consciência), analisando (percepção e atenção), montando estratégias ("Eu ia comer só que eu ia passa aqui [aponta] e ia comer", "te tranquei", "se eu colocar aqui, tu me comes e coloca ali, também", "se mexe esta também, eu te como, tu me comes, vou fazer", "tenho que ir com duas, a primeira tu vais me comer e eu passo com a segunda", "tenho que te tirar da tua casa"), 
solicitava tempo para pensar em suas jogadas ("Hum. Deixa eu pensar, deixa eu pensar, deixa eu pensar").

Analisando-se o jogo de regras, poder-se-ia afirmar que ele possibilita interações sociais que se vão modificando conforme a criança vai aprendendo e se desenvolvendo. A intervenção, por meio do jogo, permitiu à pesquisadora observar quais habilidades e conhecimentos iam atingindo o NDR e que outras ZDIs estavam sendo desenvolvidas. Para Vygotsky (2009), o que está em determinado momento na ZDI, em outro momento poderá estar no NDR, se houver aprendizagem mediada. Trabalhar na ZDI não é criar, no jogo, um nível de exigência que a criança não possa atingir no momento - mesmo que lhe seja possibilitado o apoio - ou trabalhar com um jogo em que ela não tenha nenhuma dificuldade, mas sim saber criar a dificuldade adequada para que ela, com apoio, possa resolvê-la. É saber retirar o apoio e novamente possibilitá-lo em outras jogadas, para ir promovendo a aprendizagem e o desenvolvimento da criança. Por exemplo: questionado se queria apoio em uma partida de "damas", respondeu "Sem!" e afirmou que iria realizar a jogada igual a da pesquisadora.

Com a continuidade dos encontros, parece que o sujeito foi tomando consciência de suas dificuldades, suas jogadas e sobre os problemas que elas apresentavam. Por exemplo: justificou a repetição de perguntas no jogo "cara-a-cara" dizendo "Não prestei atenção". Pode-se levantar a hipótese, pelas respostas do sujeito, de que os jogos de "memória", "cara a cara" e "damas", juntamente com a mediação da pesquisadora, possibilitaram a autoavaliação do sujeito, ilustrando a afirmação de Elkonin (2009), de que, por meio do jogo, a criança avalia-se conscientemente quanto as suas habilidades e dificuldades. A partir da tomada de consciência, percebeu-se que ele passou a imitar os comportamentos e as jogadas da pesquisadora (“Ah, que é isso! Essa jogada é igual a minha!” Vinícius riu e respondeu "É")

Para Vygotsky (1995), a imitação, tomada de forma ampla, pode ser considerada o processo principal por meio do qual ocorre a influência da aprendizagem sobre o desenvolvimento. Se a imitação se faz presente, existe a possibilidade de aprendizagem; ela é uma das vias principais do desenvolvimento das funções psicológicas superiores do ser humano, do desenvolvimento cultural da criança, e não uma simples transferência mecânica de condutas ou mera formação de hábitos. Na imitação, está implícito certo entendimento da situação; o processo de imitação pressupõe a compreensão do significado da ação do outro para poder imitá-la (VYGOTSKY, 1995, 2009). Para o autor, só podemos imitar o que está em nossa ZDI. No trabalho em colaboração, a criança pode fazer mais do que sozinha, embora não infinitamente mais, pois existem limites impostos pelo seu 
desenvolvimento e pela sua potencialidade intelectual. Para imitar, é necessário ter alguma possibilidade de ultrapassar o que eu sei para chegar ao que eu não sei.

Além dos extratos e das observações da intervenção, o desenvolvimento das FPS foi avaliado antes de iniciar a intervenção e ao seu final, por meio das questões dos subtestes da área verbal de informação, aritmética, dígitos, semelhanças e da área de execução do subteste de completar figuras do WISC III. Os resultados também indicaram que haviam ocorrido mudanças.

Analisando os resultados obtidos pelo menino na avaliação inicial, percebeu-se que, de uma maneira geral, Vinícius acertou, aproximadamente, metade das questões propostas para cada subteste, indicando dificuldades em todas as áreas investigadas (memória, atenção, percepção e raciocínio).

Os resultados obtidos após a intervenção, utilizando os mesmos subtestes - sendo reaplicados somente os itens em que a pesquisadora tinha possibilitado apoio e os que o menino não havia acertado na avaliação antes da intervenção -, indicaram que o aluno aumentou sua pontuação em todos os subtestes do WISC III.

Sugerindo que houve desenvolvimento da atenção, da memória, da capacidade de organização e reversibilidade do pensamento, do desenvolvimento da linguagem, da fluência verbal, de concentração, de organização e de raciocínio lógico, esses resultados permitem levantar a hipótese de que o aluno melhorou nas áreas já citadas, possivelmente, em decorrência da intervenção mediada com os jogos. Os avanços percebidos nas FPS repercutiram favoravelmente no desempenho escolar.

\section{Efeitos da intervenção por meio de jogos no desempenho escolar}

Os dados utilizados para análise dos efeitos da intervenção sobre o desempenho escolarforam obtidos por meio dos resultados das questões do TDE, igualmente aplicadas antes e depois das intervenções, das notas escolares da criança ao longo do ano letivo, das entrevistas realizadas após as intervenções junto à mãe, às professoras e ao próprio sujeito.

As mudanças no desempenho escolar foram constatadas nas questões do TDE, comparando-se a aplicação antes e depois da intervenção. $\mathrm{Na}$ primeira avaliação constatou-se que Vinícius apresentava muitas dificuldades na escrita, cometendo vários erros na mesma palavra, tornando-as ininteligíveis e sem possibilidade de dar-lhe apoio.

$\mathrm{Na}$ aritmética, verificou-se que ele, na maioria das questões realizadas, realizou cálculos mentais com rapidez e, em algumas situações, com o apoio de bolinhas desenhadas em uma folha de papel.

$\mathrm{Na}$ leitura, cometia vários erros em uma mesma palavra e procurava adivinhá-la lendo apenas o seu início. Sua leitura, por vezes, era ininteligível. O aluno lia com voz baixa, sendo solicitado, por diversas 
vezes, que pronunciasse mais alto as palavras; lia rápido, olhava para os lados, mexia-se na cadeira, contorcia o corpo e, várias vezes, dizia que não sabia ler.

Após a intervenção, constatou-se que houve avanços significativos, ou seja, aumentou o número de acertos na escrita, na aritmética e na leitura. As poucas dificuldades que ele demonstrou na escrita são típicas de alunos que estão em processo de alfabetização (KIGUEL, 1976); na aritmética, não conseguiu realizar as questões cujo conteúdo é da série seguinte; e na leitura, só não conseguiu ler três palavras.

As entrevistas realizadas ao final da intervenção, com a mãe e a professora, também sugeriram que ocorreram mudanças na aprendizagem de Vinícius. A mãe expôs que seu filho melhorou muito, principalmente no português: "é, ele modificou, melhorou um monte, principalmente na leitura, português. Não escrevia direito e não sabia ler. Minha mãe está admirada”. Continuando, disse que as notas foram boas, "ele está prestando atenção em aula".

A professora relatou que o aluno, a partir dos encontros, tinha modificado seu rendimento e interesse. Estava mais atento e memorizando o conteúdo. Sua leitura melhorou: "ele lia pelo desenho das palavras, mas não sabia", ele "tinha timidez", "perdeu o medo de perguntar", "não tem vergonha dos colegas", "vai até minha mesa e pergunta como se escreve; em decorrência, sua escrita melhorou". Vinícius avaliou os encontros dizendo "aprendi bastante coisa, a ler melhor, pensar melhor".

Acompanhando as notas de Vinícius, tanto a professora como a mãe e o próprio aluno reconhecem que houve uma mudança qualitativa no processo de aprendizagem. $\mathrm{O}$ aluno alfabetizou-se, realizou suas provas, demonstrando raciocínio e compreensão.

Comparando-se as informações sobre o desempenho escolar com os resultados obtidos nas questões do TDE, as notas e as falas da mãe, da professora e do próprio aluno, observaram-se alterações positivas em todas as disciplinas, possibilitando a aprovação do aluno para o $4^{\circ}$ ano.

Triangulando-se os achados da análise microgenética da intervenção com os obtidos nas questões do WISC III, no TDE, as notas escolares e entrevistas semiestruturadas, constatou-se que ocorreram mudanças positivas no desenvolvimento das FPS e, como decorrência, no desempenho escolar.

Os resultados da intervenção vieram ao encontro dos trabalhos desenvolvidos por Fittipaldi (2007, 2009) e por Pimentel (2008), cujas conclusões sugerem que o jogo mediado instiga a criança a ir além, experimentar diferentes habilidades, efetuar diferentes raciocínios, propiciando o desenvolvimento das FPS e a criação de ZDIs. Pimentel (2008) ressalta que o jogo de regras apresenta o mesmo potencial de promover modificações no psiquismo do que o jogo protagonizado, típico da pré-escola. 


\section{Efeitos da intervenção por meio de jogos no comportamento}

Os dados utilizados para análise dos efeitos da intervenção sobre o comportamento foram obtidos por meio das entrevistas realizadas junto à mãe, às professoras e ao próprio sujeito, antes e após a intervenção.

A mãe de Vinícius relata que as relações do menino com os professores eram ruins (“está a mil, não pára quieto") e também as com os colegas ("andou batendo"). A professora indicou que o aluno é agressivo e obedece às ordens somente às vezes. No geral, apresenta pouca atenção, agitação ("não fica parado"), timidez, não demonstra interesse nas atividades escolares (“só quer desenhar”).

Ao final da intervenção, tanto a mãe como a professora registraram que Vinícius modificou os cuidados de si mesmo (tomar banho, escovar os dentes, usar desodorante etc.) e seu comportamento na escola. Estava mais interessado, motivado, melhorou a irritação e o relacionamento com os pares. Sentia-se mais seguro e expressava-se melhor, passou a formar frases e a falar em um tom mais alto.

Tendo em vista o exposto, ficam evidentes as alterações no comportamento geradas pela intervenção por meio de jogos com regras junto ao aluno, principalmente no que se refere à formação da subjetividade - autoconceito relativo ao desempenho escolar e sua autoestima. À medida que Vinicius percebeu-se como capaz de aprender,melhorou a imagem de si mesmo;como decorrência,suas relações, tanto com a professora quanto com o grupo, modificaram-se. A consciência de si tem relação com a avaliação que o indivíduo faz de si mesmo. Esta consciência influenciará a forma com que ele se relacionará com o mundo e vice-versa, caracterizando-se aí uma relação dialética (FRANCO, 2009). Para Franco e Davis (2011), a escola é importante para o desenvolvimento da subjetividade e, mais especificamente, da autoestima dos sujeitos. Entendida como um fenômeno social, sendo sua construção e transformação diretamente relacionadas à qualidade das relações constituídas pelo indivíduo ao longo do seu desenvolvimento (FRANCO, 2009).

\section{Considerações finais}

A presente pesquisa conclui que o jogo com regras explícitas, no contexto de intervenções individualizadas, é um instrumento capaz de auxiliar na promoção do sucesso em estudante do $3^{\circ}$ ano do ensino fundamental com história de fracasso escolar. Encontraram-se fortes evidências de que a aprendizagem, ocorrida nas intervenções com a mediação dos jogos e da pesquisadora, promoveu o desenvolvimento das FPS (memória, atenção, percepção, raciocínio e tomada de consciência), refletindo positivamente no desempenho escolar e no comportamento. 
As conclusões foram identificadas por meio da análise de conteúdo, triangulando os dados obtidos nas entrevistas semiestruturadas junto às mães, às professoras e aos próprios alunos, os resultados das questões dos testes, as notas escolares e as observações realizadas durante as intervenções, que sofreram um processo de análise microgenética.

Ao aprender a jogar, o sujeito desenvolveu as FPS, e como, para Vygotsky (1995), essas funções formam um todo que se produz à base de conexões e relações interfuncionais, reverberaram na aprendizagem de Vinícius. As mudanças nas FPS e na aprendizagem - leitura, escrita e aritmética suscitaram alterações na formação da subjetividade do sujeito (autoconceito relativo ao desempenho escolar e autoestima). Levanta-se a hipótese de que, ao modificar sua subjetividade, processo de apropriação do mundo externo para o interno, do objetivo para o subjetivo, em uma relação dialética única, Vinícius melhorou seus relacionamentos interpessoais e os cuidados consigo próprio. Ao resgatar o interesse pelo aprender, começou a acreditar em si mesmo, fatos estes constatados quando passou a questionar a professora sobre como se escreviam as palavras; perdeu a vergonha no relacionamento entre os seus pares; começou a não responder apenas por monossílabos, formulando frases, falando em tom mais alto.

As afirmações de Vygotsky (2008), Elkonin (2009) e Leontiev (1988) referentes, principalmente, à importância do jogo protagonizado ou de papéis para o desenvolvimento psíquico na idade pré-escolar podem ser ampliadas para as crianças do ensino fundamental com histórico de fracasso escolar. O jogo mediado, na idade escolar, também modifica o desenvolvimento psíquico dos alunos; tem a capacidade de trabalhar de forma prazerosa o desenvolvimento das FPS e pode auxiliar a escola a cumprir o seu papel no desenvolvimento dessas funções. Portanto, acredita-se que as intervenções por meio de jogos, implementadas e avaliadas neste estudo, possam ser realizadas por professores em suas salas de aula, por psicólogos educacionais, psicopedagogos e outros profissionais que tenham relação com a área educacional e conhecimentos da psicologia Histórico-Cultural. Entende-se que para efetivar as intervenções por meio de jogos é necessária a mediação consciente e planejada do adulto. Não ocorrendo o jogo mediado, corre-se o risco de perder seu potencial pedagógico e desenvolvimental, tornando-o apenas uma atividade voltada à diversão.

O jogo foi um mediador eficiente entre a aprendizagem e o desenvolvimento dos sujeitos que tinham histórias de fracasso escolar. Esta conclusão reforça a ideia de que o fracasso não deve ser naturalizado, deve ser compreendido como uma construção histórica e cultural passível de ser modificada. Por fim, cabe ressaltar que os achados não devem ser generalizados, devido ao tamanho da amostra, mas devem servir como base para novas investigações a serem realizadas com outros alunos que possuam história de fracasso escolar. 


\section{Referências}

BALDAN, Merilin; ARCE, Alessandra. A Contribuição da Psicologia Histórico-Cultural no Desenvolvimento da Pedagogia do Jogo de Elkonin. In: COLÓQUIO INTERNACIONAL MARXENGELS, 5. 2007, Campinas, Anais...Campinas:Unicamp, 2007. p. 1-10. Disponível em: $<$ http://www.unicamp.br/cemarx/anais_v_coloquio_arquivos/arquivos/comunicacoes/gt5/sessao4/Meril in_Baldan.pdf>. Acesso em: 30 ago. 2011.

BALDAN, Merilin; HAI, Alessandra A. Jogo e infância em Elkonin - A Psicologia Histórico-Cultural pensando o desenvolvimento infantil. In: CONGRESSO NACIONAL DE PSICOLOGIA ESCOLAR E EDUCACIONAL, 10. 2011, Maringá, Anais... Maringá: UEM, 2011. Disponível em: <http://www.abrapee.psc.br/xconpe/trabalhos/1/148.pdf>. Acesso em: 28 ago. 2011.

DAMIANI, Magda F.; ROCHEFORT, Renato S.; CASTRO, Rafael F; DARIZ, Marion R.; PINHEIRO, Silvia S. Discutindo pesquisas do tipo intervenção pedagógica. Cadernos de EducaçãoFaculdade de Educação[da] Universidade Federal de Pelotas. Pelotas, v. 2, n. 45, p. 57-67, maio/ago. 2013. Disponível em:<http://periodicos.ufpel.edu.br/ojs2/index.php/caduc/article/view/3822>. Acesso em: 6 jun. 2014.

DUARTE, Teresa. A possibilidade da investigação a 3: reflexões sobre a triangulação (metodológica). Centro de Investigação e Estudos em Sociologia (CIES),Lisboa, n. 60, p. 1-24, 2009. Disponível em $<$ http://www.cies.iscte.pt/destaques/documents/CIES-WP60_Duarte_003.pdf>. Acesso em: 4 out. 2012.

ELKONIN, Daniil B. Psicologia do jogo. Tradução: Álvaro Cabral. 2. ed. São Paulo: Martins Fontes, 2009. 447p. (Coleção textos de Psicologia).

FIGUEIREDO, Vera. WISC III: Escala de Inteligência Wechsler para Crianças: Manual/David Wechsler,3. ed. São Paulo: Casa do Psicólogo, 2002. 322p.

FITTIPALDI, Claudia B.Jogar para ensinar - Jogar para aprender: o jogo como recurso pedagógico na construção de conceitos escolares e desenvolvimento de habilidades cognitivas, no Ensino Fundamental.2007. 236f. Tese (Doutorado em Educação: Psicologia da Educação) — Faculdade de Educação, Pontifícia Universidade Católica da São Paulo, São Paulo, 2007.

FITTIPALDI, Claudia B. Jogo e mediação social: um estudo sobre o desenvolvimento e a aprendizagem de alunos do ensino fundamental. Estudos em Avaliação Educacional, v. 20, n.42, p. 125-150, jan./abr. 2009. Disponível em: <http://www.fcc.org.br/pesquisa/publicacoes/eae/arquivos/147 1/1471.pdf>. Acesso em: 3 jul. 2010.

FRANCO, Adriana.O mito da autoestima na aprendizagem escolar.Psicologia Escolar e Educacional (ABRAPEE), Campinas, v.13, n. 2, p. 325-332, jul./dez. 2009.Disponível em: <http://dx.doi.org/10.159 0/S1413-85572009000200015>. Acesso em: 8 mar. 2014.

FRANCO, Adriana; DAVIS, Claudia.Autoestima: gênese e constituição de um atributo construído socialmente.Educação Temática Digital - ETD,Campinas, v.13, n.1, p.99-118, jul./dez. 2011. 
Disponível em: <http://www.fae.unicamp.br/revista/index.php/etd/article/view/2070>.Acesso em: 8 mar. 2014.

GÓES, Maria C. R. A abordagem microgenética na matriz histórico-cultural: uma perspectiva para o estudo da constituição da subjetividade. Cadernos Cedes, n.50, p. 9-25, abr. 2000.

LEONTIEV, Aléxis N. Os Princípios Psicológicos da Brincadeira Escolar. In: VIGOTSKII, L. S.; LURIA, A. R.; LEONTIEV,A. N.Linguagem, Desenvolvimento e Aprendizagem.Tradução: Maria da Penha Villalobos. 3. ed. São Paulo: Ícone, 1988. p. 119-142.

LINHARES, Maria B. M. et al. Avaliação Assistida: uma abordagem promissora na avaliação cognitiva de crianças. Temas em Psicologia, São Paulo, v.6, n. 3, p. 231-254, dez. 1998. Disponível em: <http://pepsic.bvsalud.org/pdf/tp/v6n3/v6n3a07.pdf>. Acesso em: 4 mar. 2011.

MINAYO, Maria C. de S. O desafio do conhecimento: pesquisa qualitativa em Saúde. 8.ed. São Paulo: Hucitec, 1993. 269p.

NASCIMENTO, Carolina P.; ARAÚJO, Elaine S.; MIGUÉIS, Marlene da R. O jogo como atividade: contribuições da teoria histórico-cultural. Psicologia Escolar Educacional, Campinas, v.13, n. 2, p. 293-302, jul./dez. 2009. Disponível em: <http://www.scielo.br/scielo.php?pid=S1413$85572009000200012 \&$ script=sci_arttext>. Acesso em: 21 ago. 2011.

NASCIMENTO, Carolina P.; ARAÚJO, Elaine S.; MIGUÉIS, Marlene da R. O jogo como atividade: contribuições da teoria histórico-cultural. Psicologia Escolar Educacional, Campinas, v.13, n. 2, p. 293-302, jul./dez. 2009. Disponível em: <http://www.scielo.br/scielo.php?pid=S141385572009000200012\&script=sci_arttext>. Acesso em: 21 ago. 2011.

PATTO, Maria H. S. A produção do Fracasso Escolar: histórias de submissão e rebeldia. São Paulo: T. A. Queiroz, 1990. 464p.

PATTO, Maria H S. Para ler as entrevistas.In: .A Cidadania negada: políticas públicas e formas de viver. São Paulo: Casa do Psicólogo, 2010. p.11-22.

PIMENTEL, Alessandra. A ludicidade na educação infantil: uma abordagem histórico-cultural. Psicologia da Educação, São Paulo, n. 26, p. 109-133, 2008. Disponível em: $<$ http://pepsic.bvsalud.org/scielo.php?script=sci_arttext\&pid=s1414-69752008000100007>.Acesso em: 21 ago. 2011.

PRESTES, Zoia R. Quando não é quase a mesma coisa: Análise de traduções de Lev Semionovitch Vigotski no Brasil Repercussões no campo educacional. 2010. 295f. Tese (Doutorado em Educação) Faculdade de Educação, Universidade de Brasília, Brasília

ROLIM, Amanda A. M.; GUERRA, Siena F. G.; TASSIGNY, Mônica M. Uma leitura de Vygotsky sobre o brincar na aprendizagem e no desenvolvimento infantil. Revista Humanidades, Fortaleza, v. 23, n. 2, p. 176-180, jul./dez. 2008. Disponível em:<http://www.slideshare.net/lucima/2633>. Acesso em: 22 ago. 2011. 
SENNA, Luiz Antônio. Formação Docente e Educação Inclusiva. Cadernos de Pesquisa, v. 38, n. 133, p. 195-219, 2008.

SOUZA, Rubens A. C. Um estudo sobre o processo de singularização de crianças através do jogo protagonizado. 2010.120f. Dissertação (Mestrado em Psicologia) — Faculdade de Psicologia, Universidade Federal do Ceará, Ceará.

VYGOTSKI, Lev. S. Obras escogidas III - Problemas del desarrollo de la psique. Madrid: Visor, 1995. $383 \mathrm{p}$.

VYGOTSKY, Lev S. Jogar e seu papel no desenvolvimento mental da criança. Tradução: Catherine Mulholland. Psikhogii Voprosy - Psicologia e Marxismo. Marxist, [S.1], 2002. Disponível em: <http://www.marxists.org/archive/vygotsky/works/1933/play.htm>. Acesso em: 14 jun. 2010.

VYGOTSKY, Lev S. A brincadeira e o seupapel no desenvolvimento psíquico dacriança. Tradução: Zoia Prestes. Revista Virtual de Gestão de Iniciativas Sociais,p.23-36,jun. 2008. Disponível em <http://xa.yimg.com/kq/groups/32960205/729519164/name/artigo+ZOIA+PRESTES>. Acesso em: 23 mar. 2011.

VIGOTSKI, Lev S. 1896-1934. A construção do pensamento e da linguagem/ Lev Semenovich Vigotsky. Tradução: Paulo Bezerra. 2. ed. São Paulo: Martins Fontes, 2009. 496p. (Biblioteca pedagógica).

YIN, Robert. Estudo de Caso: planejamento e métodos.Tradução: Ana Thorell. 4. ed. Porto Alegre: Bookman, 2010. 248p. 
The game whith rules can be an instrument to modify the school failure?

\begin{abstract}
This paper presents one of the three studies conducted on doctoral research that aimed to investigate if the game with explicit rules influences the development of higher psychological functions (HPF) of students with school failure history in elementary school. Anchored in the historicalcultural psychology. The research adopts the experimental genetic method and consists of an intervention through memory games, face to face and checkers, performed with an 11 years old student who was repeating the 3rd year of elementary school. The instruments used were semistructured interviews with family, teachers and student, report card, observation and assisted assessment of the WISC III and TDE test with the student. Data analyzes were microgenetic and thematic. The results indicate that the intervention has generated the development of HPF and changes in school performance. We conclude that the game was an effective mediator between learning and student development.
\end{abstract}

Key-words: School failure. Game. Historicalcultural psychology.

Silvia Nara Siqueira Pinheiro

E-mail: silvianarapi@gmail.com

Maria Laura de Oliveira Couto

E-mail: lauracouto@uol.com.br
¿El juego con reglas puede ser instrumento para modificar el fracaso escolar?

\section{Resumen}

Este trabajo presenta uno de los tres estudios efectuados en la investigación de doctorado que tuvo como objetivo investigar si el juego con reglas explícitas tiene influencia en el desarrollo de las funciones psicológicas superiores (FPS) de alumnos con historia de fracaso escolar en la enseñanza primaria. Tiene su respaldo en la psicología histórico-cultural. La investigación adopta el método genético-experimental y consiste en una intervención, por medio de los juegos de memoria, cara a cara y damas, realizada con un alumno de 11 años que estaba repitiendo el $3^{\circ}$ año de la enseñanza primaria. Los instrumentos utilizados fueron entrevistas semiestructuradas con la familia, profesores y alumno, boletín de calificaciones escolar, observación y evaluación asistida de los exámenes WISC III y TDE junto al alumno. Los análisis de los datos fueron microgenética y temática. Los resultados indican que la intervención generó desarrollo de las FPS y cambios en el rendimiento escolar. Se concluyó que el juego fue un mediador eficiente entre el aprendizaje y el desarrollo del alumno.

Palabras clave: Fracaso escolar. Juego. Psicología histórico-cultural.

Enviado em: 19/07/2016

Versão Final Enviada em: 09/11/2016

Aprovado em: 22/12/2016 